\title{
Risk Analysis of Transporting Hazardous Substances in Harbor Using Modeling Program
}

\author{
Sukyoung Yoon", Jayeon Yun*, Jiyun Han $^{*}$ and Seungho Jung \\ "Dept of Environmental and Safety Engineering, Ajou University, Suwon, Korea \\ 항만에서 위험물 운송 중 유해화학물질 누출 위험성에 관한 연구 \\ 윤수경* · 윤자연 · 한지윤 \\ "아주대학교 환경안전공학과
}

KEY WORDS: Port 항만, Consequence analysis 정량적 위험성평가, Hazardous materials 유해화학물질, Discharge 누출사고, Benzene 벤 젠, Toluene 톨루엔, BTX substances 방향족 화학물질, Toxic liquid 독성액체, Emergency response 비상대응, Aloha 알로하, Phast 파스트, Safeti 사페티

\begin{abstract}
Recently, the use of hazardous chemicals has been continuously increasing. Therefore, the international trade volume is growing and chemical accidents have increased. Nowadays, the safety awareness of the public has increased. As a result, the management and supervision of hazardous chemicals have been strengthened. However, the port policy of Korea has focused on increasing the volume of cargo through facility development. Thus, the port management of hazardous chemicals has been relatively neglected. For national economic growth and society, the port management of hazardous chemicals should be considered to efficiently ensure safety and economic growth. Therefore, this study assumed scenarios where hazardous materials were moved in a dangerous container, not only on appropriate wharfs but also in ports that were close to a big city. The BTX substances were selected among the toxic chemicals with large import and export volumes, and the risk distance and damage effects were predicted using various risk assessment programs. It is expected that this could be used to improve a port safety management system and could be utilized to determine the safety distance in case of an accident.
\end{abstract}

\section{1. 서 론}

화학산업의 발전으로 인하여 많은 산업 현장에서 다양한 유 해화학물질의 사용량이 증가하였다. 이에 따라 위험물질의 운 송 및 운반량 역시 증가하여 해상으로 운송되는 화학물질의 양 과 종류가 급증하였다. 우리나라 항만정책은 항만의 시설 개발 을 통한 물동량 증가, 하역생산성에만 주력하였기에, 항만 위험 물 관리에 대한 논의가 상대적으로 소홀하였다. 화학물질의 양 이 증가함에 따라 크고 작은 화학사고의 발생가능성과 위험성 이 증가하였고, 국민들의 관심도 높아졌으며, 유해화학물질 사 고의 잠재적인 위험성이 논의되기 시작하였다. 국내에서는 이 를 해결하기 위하여 화학물질관리법 및 화학물질등록 및 평가 방법에 관한 법률 등 이에 관련된 법 체계를 강화하여 화학물 질을 보다 체계적으로 사용하고 사고를 예방하기 위해 노력하 고 있다. 하지만 화학물질관리법상에서 항공, 철도, 선박은 제외
되어 있어 법적 사각지대에 놓여있는 상태이다.

국내 화학 산업은 1,770 억 달러 규모로 세계 5 위로 성장하였 다(2013년 생산액 기준). 성장한 규모에 비해 국내 화학산업의 취급시설은 노후되었고, 대량 유통되는 화학물질로 인하여 사 고의 발생 가능성은 더욱 높아지고 있다. 또한 많은 종류의 화 학물질이 유통되고 있으며 이에 따라 물질마다 각각 다른 조건 (온도, 압력, 기상 등)에서 다른 방식의 관리가 필요하다. 국내 항만에서는 많은 위험물이 유통되고 있는데, 이러한 위험물의 취급장소가 주거지역과 근접해 있어 사고 발생 시 위험을 키울 수 있는 요인들이 많다(Kim et al, 2016).

일반적으로 해상으로 운송되는 화학물질 중 산적 형태 위험물 의 경우, 보통 울산항, 태안항 등의 HNS(Hazardous and noxious substances) 저장시설이 있는 전용부두를 통한다. 하지만 포장형 태의 유해화학물질의 경우, 위험물 컨테이너 형태로 운송되며, 인구 밀집도가 높은 대도시와 인접해 있는 부산항, 인천항 등의

Received 29 November 2017, revised 24 June 2018, accepted 2 August 2018

Corresponding author Seungho Jung: +82-31-219-2401, processsafety@ajou.ac.kr ORCID: https://orcid.org/0000-0002-1355-4833

(c) 2018, The Korean Society of Ocean Engineers

This is an open access article distributed under the terms of the creative commons attribution non-commercial license (http://creativecommons.org/licenses/by-nc/3.0) which permits unrestricted non-commercial use, distribution, and reproduction in any medium, provided the original work is properly cited. 
항만으로 출입되기 때문에 사고 발생 시 주거 및 생활지역에 직 간접적인 영향을 끼칠 수 있다(Woo and Lee, 2016).

이에 본 연구는 BTX(Benzene, Toluene, Xylene) 물질 중 벤젠 과 톨루엔을 선정하였고, 화학물질을 항만에서 컨테이너로 운 송하는 경우 하역, 적재 작업 도중 유해화학물질이 누출된 경우 의 시나리오를 다양한 위험성평가 프로그램을 사용하여 피해영 향범위를 산정하였다.

\section{2. 방법론}

\section{1 대상물질 선정}

유해화학물질관리법 제 2 조에 의하면 “사고대비물질”이란 급 성독성, 폭발성 등이 강하여 사고 발생의 가능성이 높거나 사고 가 발생한 경우에 그 피해 규모가 클 것으로 우려되는 화학물 질로서 사고 대비 및 대응 계획이 필요하다고 인정될 정도의 치명적인 물질이다. BTX 물질은 사고대비물질이며 동시에 위 험물안전관리법상 위험물에 해당되는 물질이다. 일반적으로 1,000 톤 이상 수출, 수입되는 상위 물질에는 원유제품이 주를 이루고 있다. 이를 제외한 화학물질 중에서 BTX 물질은 기초화 학제품으로서 상위에 해당한다.

따라서, 본 연구에서는 최근 항만에서 비교적 사고가 잦은 물 질 중 수입 및 수출양이 많으며, 국내 7개 유역(지방)환경청에 서 가장 사용량이 많은 BTX 물질 중 벤젠과 톨루엔을 선정하 였다.

BTX 물질은 기초화학물질부터 석유화학제품까지 다양한 형 태로(합성, 분리, 정제) 취급되기 때문에 실제 사용량은 통계치 보다 훨씬 많을 것으로 판단되며, 이에 따른 BTX 물질의 관리 가 중요하다(Ministry of Environment, 2007). 특히, 자일렌은 이 성질체(p,m,o-xylene)로 존재하여 위험성평가 프로그램을 이용해 시뮬레이션 할 때 일정한 형태의 결과가 나타나지 않는다.

이에 보수적인 결과를 도출하고자 벤젠과 톨루엔을 대표물질 로 선정하였다. 항만 지역 내 위험물 컨테이너의 운영관리제도는 국제해사기구가 제정한 국제해상위험물규칙(International maritime dangerous goods cord, IMDG cord) 등의 국제 협약에 기초를 두고 있으며, 이에 대한 정보는 Table 1에 나타내었다(Ministry of Oceans and Fisheries, 2016; IMO, 2014). 항만에서의 유해화학물질 사고는 Table 2(Kim, 2015)에 연간 1,000 톤 이상 수출, 수입되는 물질의 근거는 Table 3에 나타내었다(Ministry of Environment, 2007).

Table 1 IMDG code of benzene and toluene

\begin{tabular}{|c|c|c|}
\hline Material & IMDG code & $\begin{array}{c}\text { Dangerous goods } \\
\text { safety management act }\end{array}$ \\
\hline Benzene & & $\begin{array}{c}\text { Flammable liquids } \\
\text { (Category 4. } 1 \text { Petroleum) }\end{array}$ \\
\hline Toluene & Class 3 & $\begin{array}{c}\text { Flammable liquids } \\
\text { (Category 4. } 1 \text { Petroleum) }\end{array}$ \\
\hline
\end{tabular}

Table 2 Hazardous chemical accidents in ports 2011 2015

\begin{tabular}{|c|c|c|c|c|}
\hline No. & Area & Date & Location & Material \\
\hline 1 & \multirow{5}{*}{ Ul-san } & ‘11.01.09 & Port 4 wharf & p-xylene \\
\hline 2 & & ‘11.03.11 & Port 3 wharf & p-xylene \\
\hline 3 & & ‘'13.12.29 & Port 24 miles area & unknown \\
\hline 4 & & '14.07.17 & Port 4 , Pier 2 & unknown \\
\hline 5 & & ‘'15.01.11 & Port 4 wharf & unknown \\
\hline 6 & \multirow{5}{*}{ Yeo-su } & ‘11.02.17 & Zhongheung Pier & Octanol \\
\hline 7 & & ‘ 12.10 .26 & $\begin{array}{c}\text { Gwangyang Port } \\
\text { Anchorage }\end{array}$ & Creosote oil \\
\hline 8 & & ‘13.01.29 & Yeosu & Methanol \\
\hline 9 & & ‘'13.07.16 & LG Chemical & $\begin{array}{l}\text { Sodium } \\
\text { hydroxide }\end{array}$ \\
\hline 10 & & ‘'13.09.17 & Petrochemical Pier & $\begin{array}{l}\text { Benzene } \\
\text { mixture }\end{array}$ \\
\hline 11 & Wan-do & ‘11.03.16 & Southern Sea & Benzene \\
\hline 12 & Pyeong-taek & '12.11.10 & Pyeong-taek & Palm oil \\
\hline 13 & Tong-yeong & ‘'13.06.14 & Tong-yeong & Formalin \\
\hline 14 & Dae-san & ‘14.05.22 & $\begin{array}{l}\text { Samsung } \\
\text { Total Pier }\end{array}$ & $\begin{array}{c}\text { p-dimethylb } \\
\text { enzene }\end{array}$ \\
\hline
\end{tabular}

Table 3 Ranking of import \& export volume

\begin{tabular}{ccc}
\hline \hline Material & $\begin{array}{c}\text { Ranking of } \\
\text { import volume (No.) }\end{array}$ & $\begin{array}{c}\text { Ranking of } \\
\text { export volume (No.) }\end{array}$ \\
\hline Benzene & 28 & 9 \\
Toluene & 31 & 28 \\
Xylene & 12 & 12 \\
\hline
\end{tabular}

\section{2 누출 시나리오 선정}

\subsection{1 대상물질 및 시나리오 선정}

위험물은 일반적으로 사회생활을 영위하는 데 있어 필요한 물질 중 취급 부주의로 화재, 폭발, 중독, 방사성 장애, 부식 등 의 위험을 초래하여 인간 및 재산에 직접적인 악영향을 주는 물질을 말하며(Kim et al, 2016), 항만이란 부두지역과 항만 배 후지역에 추가하여 선박이 입출항하고 정박하며 채널을 따라 부두에 접안하는 공간인 항구를 통틀어 지칭한다. 이 때, BTX 물질은 항만위험물로서, 해상운송 및 육상운송의 연결지점인 항만지역에서 위험물 사고가 발생한다면 파급효과는 매우 다양 하고 클 것이며, 이는 최종적으로 경제 위기 등을 초래할 수도 있다.

국내의 화학사고 발생 현황은 Fig. 1에 따르면, 전체 화학사고 중 누출 233 건(약 $72 \%$ ), 폭발 44 건(약 $14 \%$ )으로 대부분의 화학 사고는 누출사고임을 알 수 있다(Oak et al., 2017). 


\section{Status of chemical accidents by accidents type}

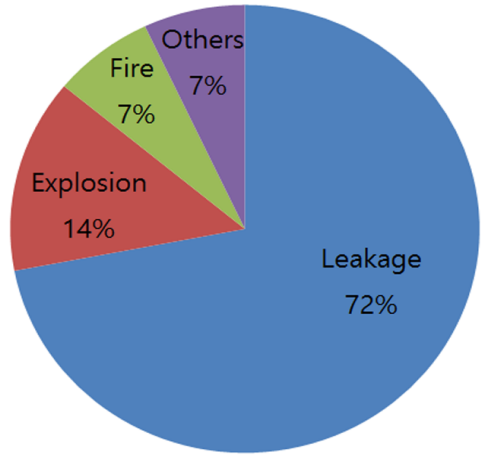

Fig. 1 Status of chemical accidents by accident type

항만 위험물 누출사고는 수송수단 고유의 고장이나 적재 및 하 역 활동(외부 영향에 의한 것)으로 나눌 수 있는데(Lees, 1996) 이 중 환적 상황 시 충돌 LOC(Loss of containment)가 고려 될 경우의 누출 시나리오로 선정하였다.

\subsection{2 대상 지역 및 조건 설정}

위험물은 보통 전용부두를 통하여 산적 형태로 이동한다. 하지만 본 연구에서는 대도시와 밀접해 있는 항만에서 위험물 누출 시의 위험성을 알아보기 위하여 위험물 컨테이너 형태로 항만으로 운송되

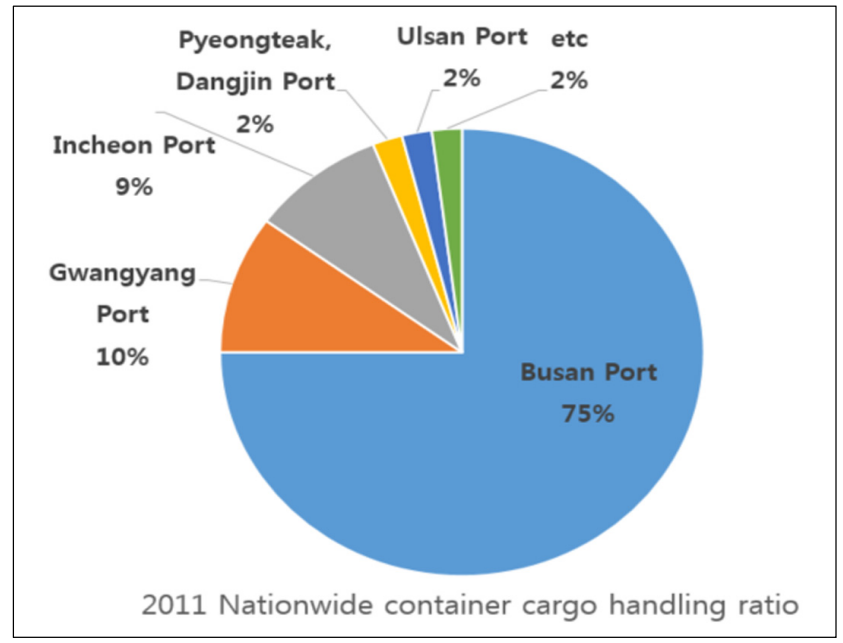

Fig. 2 Nationwide container cargo handling ratio in 2011

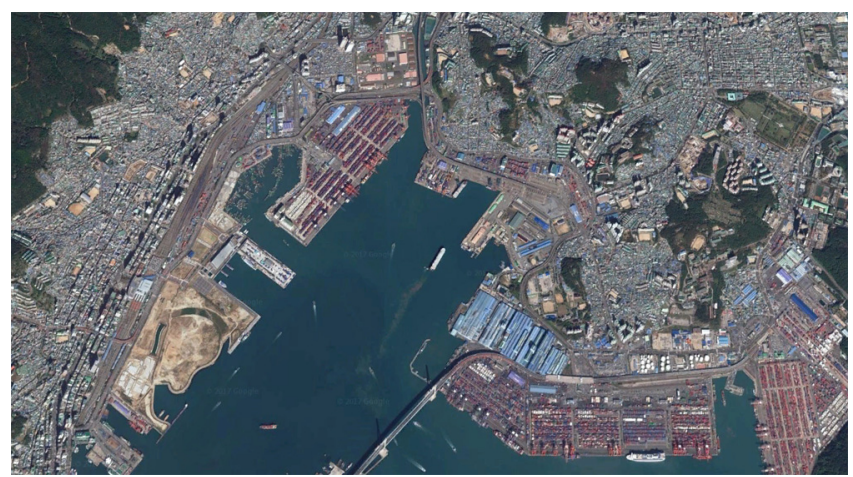

Fig. 3 Location of Busan Port
Table 4 Container loading specification

(Dry container, Unit : ton/cubic meter)

\begin{tabular}{cccc}
\hline \hline Standard & Size $(\mathrm{W} \times \mathrm{H} \times \mathrm{L})$ & $\begin{array}{c}\text { Maximum loading } \\
\text { weight }(\text { ISO) }\end{array}$ & $\begin{array}{c}\text { Actual maximum } \\
\text { weight }\end{array}$ \\
\hline $20 \mathrm{ft}$ & $2.4 \times 2.4 \times 6(\mathrm{~m})$ & 20.32 & 17.5 \\
\hline $40 \mathrm{ft}$ & $2.4 \times 2.4 \times 12(\mathrm{~m})$ & 30.48 & 20.0 \\
\hline
\end{tabular}

는 경우로 가정하였으며, 우리나라의 대표적 항만 중 전체 컨테이너 처리물량의 $76.9 \%$ 를 차지하는 부산항에서의 영향성 평가를 실시하 였다. 이를 Fig. 2에 나타내었으며, Fig. 3은 부산항의 지도를 나타낸다.

시나리오의 기본적인 조건으로는 보수적인 영향범위를 산정 하기 위하여 한국산업안전보건공단(KOSHA, Korea Occupational Safety \& Health Agency)에서 제정한 “사고 시나리오 선정에 관 한 기술지침”을 적용하여 독성물질 누출 시 피해영향 범위를 산 정하였다. 일반적으로 해상운송에서 사용하는 위험물 컨테이너 는 일반적인 컨테이너의 형태와 탱크컨테이너(탱크테이너)의 형 태로 구분되며 일반 컨테이너의 경우 $20 \mathrm{ft}(2.4 \times 2.4 \times 6(\mathrm{~m})), 40 \mathrm{ft}$ $(2.4 \times 2.4 \times 12(\mathrm{~m}))$ 등이 주로 사용되고 있으며 탱크테이너의 경우 에는 $20 \mathrm{ft}$ 용량과 거의 유사하게 사용되고 있다(Kang, 2014). 이 는 국제적으로 유통되고 있는 국제표준기구(ISO, International Organization for Standardization)의 표준 규격을 사용하도록 권고 하고 있으며, Table 4는 이를 나타낸다.

본 연구는 컨테이너 선박의 적재 능력의 표시기준(Twenty- foot equivalent unit, TEU)이 되는 $20 \mathrm{ft}(2.4 \times 2.4 \times 6(\mathrm{~m}))$ 컨테이너를 기준 으로 하였다(Kim et al., 1998). 이론상으로 $20 \mathrm{ft}$ 컨테이너에는 약 20 톤까지 적재할 수 있기에 KOSHA Guide의 최악의 누출 시나리 오(NICS, 2016)에 적용하여 대량누출의 경우 20 톤의 BTX 물질이 10 분 전량 누출되고, 기상 조건 역시 위의 기술지침에 따라 상온 상압 $\left(25^{\circ} \mathrm{C}, 1\right.$ 기압)에서 밤, 낮의 풍속은 각각 $1.5 \mathrm{~m} / \mathrm{s}, 5 \mathrm{~m} / \mathrm{s}$ 로 가정 하였으며, 특히 이 경우는 컨테이너의 일종인 탱크테이너를 단일 용기로 가정하여 전량누출된 것으로 가정하였다. 소량 누출일 경 우는 RIVM(Reference manual Bevi risk assessments)에 따라 $30 \mathrm{~m}^{3}$ 이 누출된다고 가정하였다. 이 때 온도의 변화에 따른 영향범위는 크게 다르지 않아 이를 낮과 밤의 풍속을 기준으로 비교하였다.

$$
R_{R}=\frac{Q_{R}}{10}
$$

여기서 $R_{R}$ 은 누출률 $(\mathrm{kg} / \mathrm{min})$ 이고, $Q_{R}$ 은 누출량 $(\mathrm{kg})$ 이다.

Table 5 LOCs for ships in an establishment

\begin{tabular}{|c|c|c|c|c|}
\hline Ship & $\begin{array}{l}\text { L.1 } \\
\text { ull bore arm }\end{array}$ & $\begin{array}{c}\text { L.2 } \\
\text { Leak arm }\end{array}$ & $\begin{array}{c}\text { E.1 } \\
\text { External } \\
\text { large spill }\end{array}$ & $\begin{array}{c}\text { E.2 } \\
\text { External } \\
\text { small spill }\end{array}$ \\
\hline $\begin{array}{l}\text { Single- } \\
\text { walled } \\
\text { iquid tanker }\end{array}$ & $\begin{array}{c}6 \times 10^{-5} \\
\text { per } \\
\text { transshipment }\end{array}$ & $\begin{array}{c}6 \times 10^{-4} \\
\text { per } \\
\text { transshipment }\end{array}$ & $f_{0}$ & 0.2 \\
\hline $\begin{array}{l}\text { Double- } \\
\text { walled } \\
\text { liquid tanker }\end{array}$ & $\begin{array}{c}6 \times 10^{-5} \\
\text { per } \\
\text { transshipment }\end{array}$ & $\begin{array}{c}6 \times 10^{-4} \\
\text { per } \\
\text { transshipment }\end{array}$ & $0.006 \times \mathrm{f}_{0}$ & $0.0015 \times \mathrm{f}_{0}$ \\
\hline $\begin{array}{l}\text { Gas tanker, } \\
\text { Semi- } \\
\text { gas tanker }\end{array}$ & $\begin{array}{c}6 \times 10^{-5} \\
\text { per } \\
\text { transshipment }\end{array}$ & $\begin{array}{c}6 \times 10^{-4} \\
\text { per } \\
\text { transshipment }\end{array}$ & $.025 \times \mathrm{f}_{0}$ & $.00012 \times \mathrm{f}_{0}$ \\
\hline
\end{tabular}


Table 6 Frequencies of LOCs for ships in an establishment

$$
\text { LOC for ships in an establishment }
$$

L.1 Full bore rupture of the loading/unloading arm outflow from both sides of the full bore rupture

Leak of the loading/unloading arm

L.2 outflow from a leak with an effective diameter equal to $10 \%$ of the nominal diameter, with a maximum of $50 \mathrm{~mm}$

\section{External impact, large spill}

Gas tanker continuous release of $180 \mathrm{~m}^{3}$ in $1800 \mathrm{~s}$

Semi-gas tanker

E.1 (refrigerated) continuous release of $126 \mathrm{~m}^{3}$ in $1800 \mathrm{~s}$

Single-walled liquid tanker

continuous release of $75 \mathrm{~m}^{3}$ in $1800 \mathrm{~s}$

Double-walled liquid tanker

continuous release of $75 \mathrm{~m}^{3}$ in $1800 \mathrm{~s}$

External impact, small spill

Gas tanker continuous release of $90 \mathrm{~m}^{3}$ in $1800 \mathrm{~s}$

Semi-gas tanker

E.2 (refrigerated) continuous release of $32 \mathrm{~m}^{3}$ in $1800 \mathrm{~s}$

Single-walled liquid tanker

continuous release of $30 \mathrm{~m}^{3}$ in $1800 \mathrm{~s}$

Double-walled liquid tanker

대상지역이 부산항만이라는 지역적 특성을 고려하여 풍향은 기상청의 방재기상연보를 통하여 2016년 월별, 시간별 평균 풍 속을 고려하였고(Meteorological Administration, 2017), 사고 빈도 는 선박에 대한 누출사고 빈도를 적용하였으며(RIVM, 2009), 이 를 Table 5, Table 6에 이를 나타내었다.

$$
f_{0}=6.7 \times 10^{-11} \times T \times t \times N
$$

여기서 $T$ 는 연간입출항선박수, $t$ 는 선박별하역평균시간, $N$ 은 연간환적수이다.

식 (2)를 통해 사고 빈도를 최종적으로 구할 수 있다. 이 때, 연간입출항선박수 $(T)$ 는 해양수산부의 부산지방해양수산청의 2016년 통계자료를 이용하여 193,312건, 선박별하역평균시간 $(t)$ 은 부산지방해양수산청의 2016년 통계자료인 항만하역능력현황 $354,015,000 \mathrm{ton} / \mathrm{year}$ 과 부산항만공사의 2016년 통계자료인 $20 \mathrm{ft}$ 컨테이너 실적을 이용하여 $4.4 \mathrm{hr} /$ 척을 구하였다. 연간환적수 $(N)$ 는 해양 수산부의 부산 지방 해양수산청의 2016년 통계 자료를 이용하여 $f_{0}$ 를 구하고(Ministry of Oceans and Fisheries, 2017), 이를 외부 충격으로 인한 대량 누출, 소량 누출 두 가지의 경우 로 가정하여 최종 사고 빈도는 대량누출의 경우 0.0325 , 소량누 출의 경우 0.065 를 적용하여 IR(Individual risk)을 구하였다. 더 불어 인구 및 인구밀도는 국가통계포털(KOSIS, 2017)을 통하여 부산 남구의 인구밀도와 낮, 밤에 따른 주간인구와 상주인구를 각각 따로 적용하여 위험성 평가를 수행하였으며 이에 대한 정 확한 수치는 Table 7, Table 8에 명시하였다(NFPA, 2017).

\section{3 영향성 평가(Consequence assessment)}

비상대피 거리 산정을 위하여 프로그램 ALOHA(Areal location of hazardous atmospheres)와 Phast v6.7을 사용하였으며, 개인적 인 위험도를 구하기 위하여 Safeti v6.7을 사용하였다.

ALOHA는 미국 해양대기국(National Oceanic and Atmospheric Administration)이 개발하여, 환경보호청(Environmental Protection Agency)과 공동으로 활용하는 피해 예측 프로그램으로 무료 배 포하고 있는 프로그램이다.

Gaussian 및 DEGADIS(Dense gas dispersion model) 누출 모델 을 사용하여 화학물질 별로 영향범위를 산정하는데 풍부한 Data base가 있고, 모델의 결과 Google Earth를 통하여 피해영향 범위 를 지도상에 직접 표출할 수 있으며 접근성이 높다는 장점이 있 다(NICS, 2015). 하지만 지형변화, 화학반응 모사 등이 비교적 어렵다는 제한사항이 있어 보다 정확한 값을 비교하기 위해 DNV-GL사의 상용 프로그램인 Phast v6.7을 사용하여 출력된 값 을 비교하였다.

최종적으로는, 정량적 소프트웨어인 DNV-GL사의 Safeti v6.7 을 사용하여 피해범위 예측 및 사고 빈도를 분석하였고, 위험도 산정방법을 제시하였다.

\section{3. 결과 및 분석}

대량 누출은 $20 \mathrm{ft}(2.4 \times 2.4 \times 6(\mathrm{~m}))$ 의 위험물 탱크테이너에서 벤 젠과 톨루엔이 전량 누출되었을 경우로, 소량 누출은 $30 \mathrm{~m}^{3}$ 의 양 이 누출 되었을 경우로 하여, 기상, 인구, 지형 조건에 따른 비 상대피 거리를 산출하였고, 이 때 조건 및 입력 값은 Table 7과 Table 8에 나타내었다(KOSHA, 2017).

Table 9는 프로그램 ALOHA와 Phast v6.7을 통하여 구한 ERPG-2 거리 값을 비교한 것이다.

\begin{tabular}{|c|c|}
\hline Material & Benzene \\
\hline CAS No. & $71-43-2$ \\
\hline Molecular formula & $\mathrm{C}_{6} \mathrm{H}_{6}$ \\
\hline Density & 0.88 \\
\hline NFPA & Flammability 3 \\
\hline Temperature & $25^{\circ} \mathrm{C}$ \\
\hline \multirow{2}{*}{ Wind speed } & $5 \mathrm{~m} / \mathrm{s}, \mathrm{D}$ \\
\hline & $1.5 \mathrm{~m} / \mathrm{s}, \mathrm{F}$ \\
\hline Density of population & 10,455 people $/ \mathrm{km}^{2}$ \\
\hline Frequency & $0.0006 /$ transshipment \\
\hline \multirow{2}{*}{ Population } & 284,734 people \\
\hline & 287,985 people \\
\hline Source & Direct \\
\hline Type & Continuous \\
\hline The duration time & 10 mins \\
\hline Ground roughness & Open country \\
\hline
\end{tabular}

Table 7 Input data of consequence assessment (Benzene) 
Table 8 Input data of consequence assessment (Toluene)

\begin{tabular}{|c|c|}
\hline Material & Toluene \\
\hline CAS No. & $108-88-3$ \\
\hline Molecular formula & $\mathrm{C}_{6} \mathrm{H}_{5} \mathrm{CH}_{3}$ \\
\hline Density & 0.8636 \\
\hline NFPA & Flammability 3 \\
\hline Temperature & $25^{\circ} \mathrm{C}$ \\
\hline \multirow{2}{*}{ Wind speed } & $5 \mathrm{~m} / \mathrm{s}, \mathrm{D}$ \\
\hline & $1.5 \mathrm{~m} / \mathrm{s}, \mathrm{F}$ \\
\hline Density of population & 10,455 people $/ \mathrm{km}^{2}$ \\
\hline Frequency & 0.0006 / transshipment \\
\hline \multirow{2}{*}{ Population } & 284,734 people \\
\hline & 287,985 people \\
\hline Source & Direct \\
\hline Type & Continuous \\
\hline The duration time & $10 \mathrm{mins}$ \\
\hline Ground roughness & Open country \\
\hline
\end{tabular}

Table 9 ERPG-2 from Consequence Assessment

\begin{tabular}{cccc}
\hline \hline \multirow{2}{*}{ Material } & \multirow{2}{*}{ Program } & \multicolumn{2}{c}{ ERPG-2 [m] } \\
& & Day & Night \\
\hline \multirow{2}{*}{ Benzene } & ALOHA & 494 & 780 \\
& Phast v6.7 & 319 & 747 \\
\hline \multirow{2}{*}{ Toluene } & ALOHA & 231 & 358 \\
& Phast v6.7 & 128 & 286 \\
\hline
\end{tabular}

ERPG-2(ppm)는 대피 거리 기준이 되는 끝점 농도로, 거의 모 든 사람들이 1 시간 동안 노출되어도 보호조치를 취할 수 있는 능력을 손실할 수 있는 경험, 회복 불능 상태로의 발전 등 기타 심각한 건강에 대한 영향이나 징후가 나타나지 않는 최고 농도 를 말한다(AIHA, 2016).

밤과 낮으로 나누어 비교하였을 때, ALOHA의 프로그램 특성 상 Phast v6.7보다 더 보수적인 결과가 나왔다. 이는 Table 9을 통해 확인할 수 있으며, Fig. 4와 Fig. 5는 이를 ALOHA를 이용 하여 Mapping한 것이다.

Fig. 3의 지도를 보면 알 수 있듯이, 부산항의 항만은 인근 주 거지역과 매우 가깝기 때문에 사고가 발생할 경우 사회적 위험 도(Societal risk, SR)는 매우 높음을 알 수 있다.

따라서 본 연구에서는 사회적 위험도(SR)를 제외한 사고 발 생 시 주거지역의 개인에게 미칠 수 있는 위험성을 알 수 있는 개인적 위험도(Individual risk, IR)(Martins et al., 2016)를 외부 충 격이 있을 수 있다는 전제하에 대량 누출과 소량 누출의 경우 로 나누어 Contour를 그림으로 나타내었다. 이때 대량 누출의 경우는 KOSHA의 최악의 시나리오를 기반으로 위험물컨테이너 의 일종인 탱크테이너에서의 누출상황을 가정하였으며 이와 비 교하기 위한 소량 누출일 경우는 RIVM에 따라 $30 \mathrm{~m}^{3}$ 의 양이 누 출된다고 가정하였다.

국제화재방지협회(National Fire Protection Association, NFPA) 의 위험도 기준을 활용하여 개인적 위험도(IR)의 허용 여부를 판

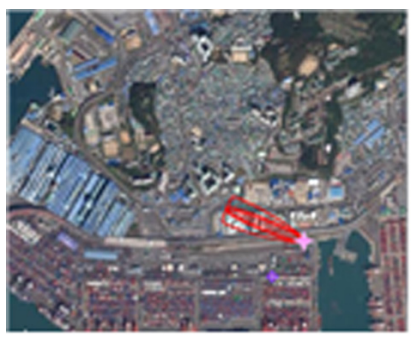

(a) Day

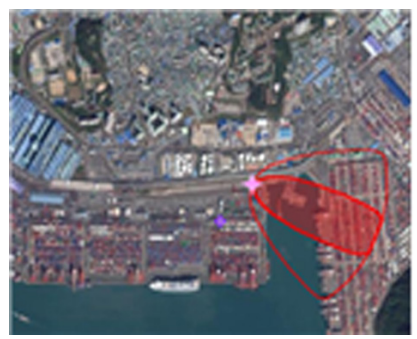

(b) Night
Fig. 4 Mapping of a dispersion range (Benzene)

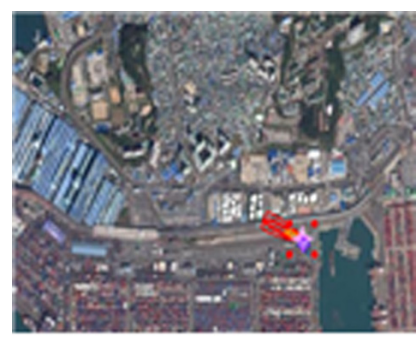

(a) Day

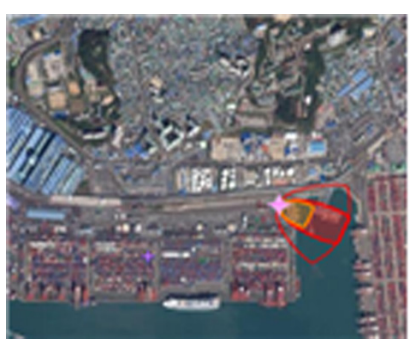

(b) Night
Fig. 5 Mapping of a dispersion range (Toluene)

단할 수 있는 위험도는 다음 Table 10에 나타내었고(Kang et al., 2017), Figs. 6-9는 각각의 상황의 개인적 위험도(IR)를 Contour로 나타낸 것이다.

본 연구는 부산 남구의 인구분포 및 밤, 낮 인구를 적용하여 개 인적인 위험도(IR)를 나타내었다. 누출사고시 계절별 영향범위는 온도의 변화만 있을 뿐 큰 차이가 나타나지 않았고, 풍속의 영향 이 강한 것을 볼 수 있어 낮과 밤으로만 나누어 이를 비교하였다. 사고 빈도는 선박에서 환적 중 누출되는 사고의 빈도를 이용하였 는데(Uijt de Haag and Ale, 2005) Zone 1은 IR $\leq 1.0 \mathrm{E}-05 /$ year이 기준이며 Zone 2 는 $1.0 \mathrm{E}-06 /$ year $\leq \mathrm{IR} \leq 1.0 \mathrm{E}-05 /$ year이고 Zone 3 은 3.0E-07/year $\leq \mathrm{IR} \leq 1.0 \mathrm{E}-06 /$ year로 나타난다.

Table 10 Criteria for tolerability of individual risk (IR)

\begin{tabular}{|c|c|c|}
\hline Classification & Individual Risk & Remarks \\
\hline Zone 1 & $\begin{array}{c}\mathrm{IR} \leq \\
1.0 \mathrm{E}-05 / \text { year }\end{array}$ & $\begin{array}{l}\text { Not permitted : residential, } \\
\text { office, and retail permitted : } \\
\text { Occasionally occupied } \\
\text { developments(e.g., pump houses, } \\
\text { transformer stations) }\end{array}$ \\
\hline Zone 2 & $\begin{array}{c}1.0 \mathrm{E}-06 / \text { year } \\
\leq \mathrm{IR} \leq \\
1.0 \mathrm{E}-05 / \text { year }\end{array}$ & $\begin{array}{l}\text { Not permitted : Shopping } \\
\text { centers, large-scale retail outlets, } \\
\text { etc permitted : Wok places, } \\
\text { retail and ancillary services, } \\
\text { residences in areas of } 28 \text { to } 90 \\
\text { persons/hectare density }\end{array}$ \\
\hline Zone 3 & $\begin{array}{c}3.0 \mathrm{E}-07 / \text { year } \\
\leq \mathrm{IR} \leq \\
1.0 \mathrm{E}-06 / \text { year }\end{array}$ & $\begin{array}{c}\text { Not permitted : Churches, } \\
\text { school, hospitals, major public } \\
\text { assembly area, and other } \\
\text { sensitive establishment } \\
\text { permitted : All other structures } \\
\text { and activities. }\end{array}$ \\
\hline
\end{tabular}


항만지역의 지역적인 특성에 따라 밤에는 육풍에 의하여 육 지에서 바다로, 낮에는 해풍에 의하여 바다에서 육지로 바람이 부는 것을 Contour를 통하여 확인할 수 있었다. 일반적으로 밤 의 기상조건에서 독성물질이 대기 중에 빠르게 확산되기 때문

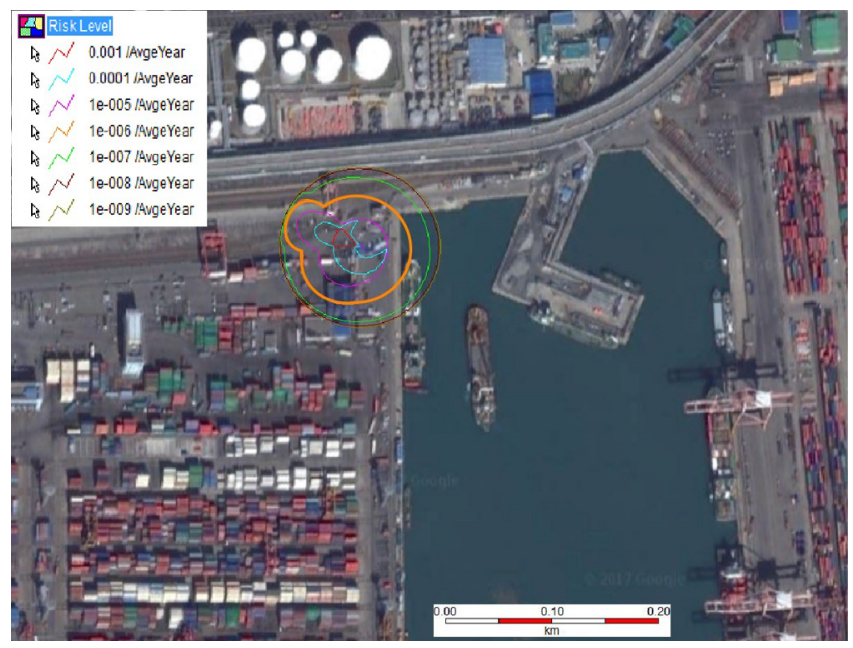

Fig. 6 Individual risk contour level (External large spill / Day)

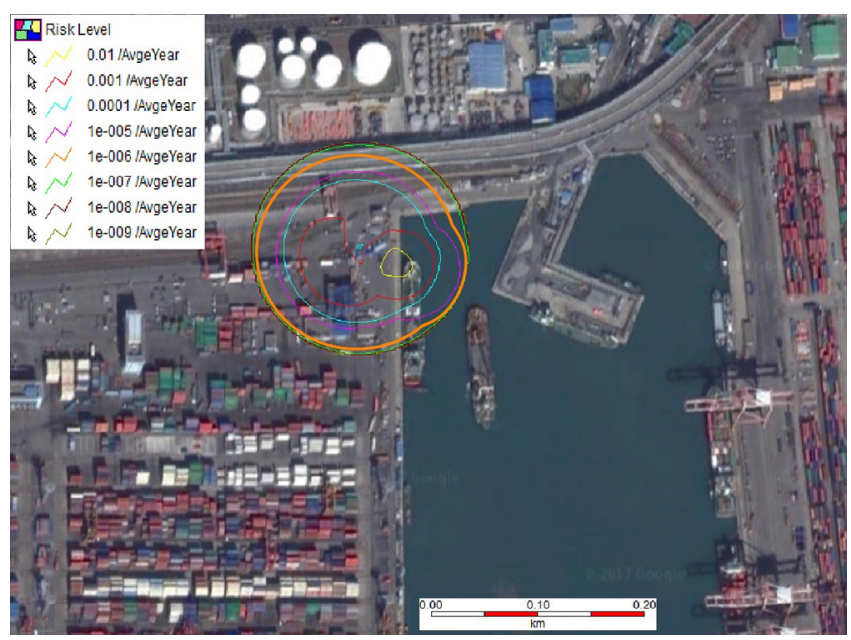

Fig. 7 Individual risk contour level (External large spill / Night)

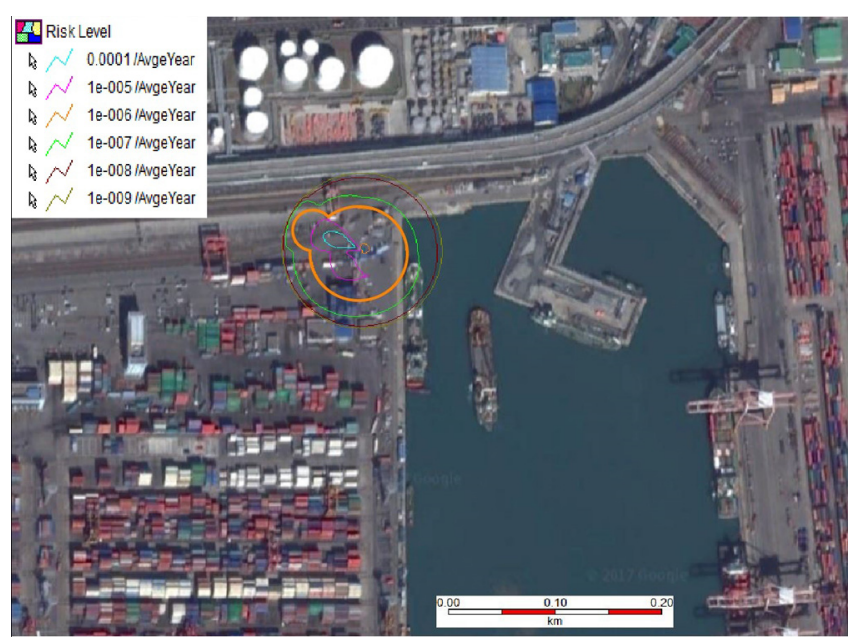

Fig. 8 Individual risk contour level (External small spill / Day)

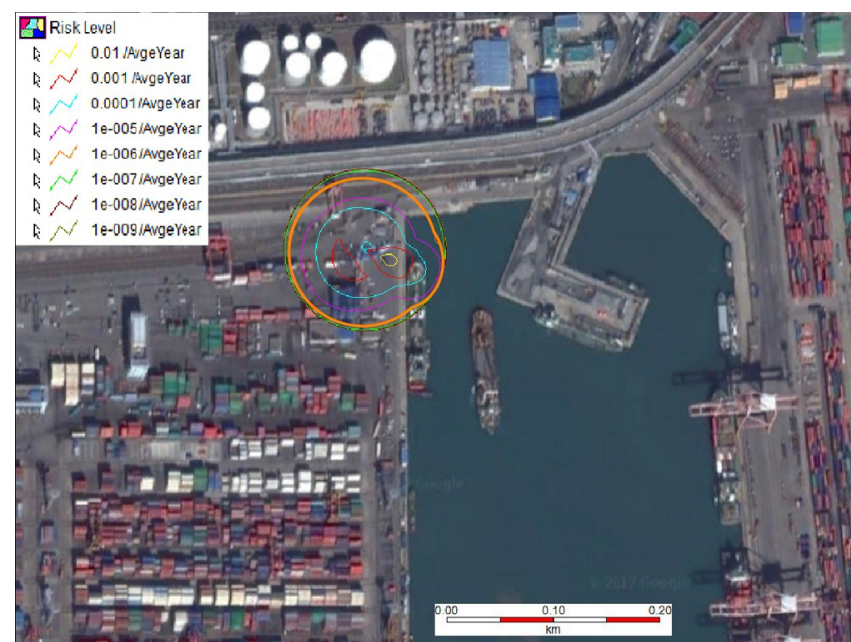

Fig. 9 Individual risk contour level (External small spill / Night)

에 더 큰 영향을 보였다. 주변지역에 학교와 주거지역이 위치해 있고 도심지역이 위치하였기 때문에 주간인구와 상주인구의 차 이가 거의 없었다. 따라서 인구 차이로 인한 밤낮의 차이는 거 의 없다고 볼 수 있다. 개인적 위험도(IR)는 외부 충격으로 인한 대량 누출 시 밤의 경우, $2.32 \mathrm{E}+02 / y e a r$, 낮의 경우, 3.1E-08/year 로 계산되었으며, 외부 충격으로 인한 소량 누출 시 밤의 경우 $8.19 \mathrm{E}+0 /$ year, 낮의 경우, $1.75 \mathrm{E}-09 / \mathrm{year}$ 로 $\mathrm{NFPA}$ 의 허용 가능한 범위에 포함되는 것을 확인할 수 있었다. 또한 RIVM에 따라 네 덜란드 기준을 확인해보면 개인적 위험도(IR)를 $10^{-6} / y e a r$ 로 제한 하고 있다. Figs. 6-9의 주황색 원은 이를 나타내는데 이 원에 표 시된 부분이 주거지역에 영향을 주지 않아 비교적 위험성이 적 다는 사실을 알 수 있었다.

\section{4. 결 론}

본 연구는 항만에서 BTX 물질 중 벤젠과 톨루엔의 누출사고 를 가정하여 피해영향범위 및 개인적 위험도(IR)를 구하였다.

우리나라와 달리 외국 선진항만의 경우, 항만 지역 내 위험물 컨테이너의 운영관리제도는 국제해사기구가 제정한 국제해상위 험물규칙 등의 국제협약에 그 기초를 두고 있다. 현재 우리나라 의 항만하역 산업은 수출입 화물의 $99 \%$ 이상을 처리하는 관문 역할을 하고 있으며 항만처리 물동량은 약 15 억 톤으로 계속 증가하고 있다. 하지만 우리나라의 항만 안전 상황은 비교적 선 진화되어있지 못하며, 항만에서 주거지역은 매우 가까이 위치 한 경향을 볼 수 있다. CA(Consequence assessment) 결과 부산 컨테이너 터미널에서 20 톤의 BTX 물질 중 벤젠과 톨루엔이 누 출되었을 경우 항만에서 1 시간 동안 노출되었을 때 거의 모든 사람이 보호조치 불능의 증상을 유발하거나 회복 불가능 또는 심각한 건강상의 영향이 나타나지 않는 공기 중 최대 농도인 ERPG-2 농도보다 높은 농도에 노출되는 것으로 나타났다. 하지 만 개인적 위험도(IR)는 항만 내에서만 형성되는 것으로 나타났 고 주거지역에는 특별한 영향이 미치지 않는 것을 확인할 수 있었다.

따라서 항만 내 근로자의 비상대피거리 및 개인적 위험도(IR) 를 예측 및 분석할 수 있으나, 주거지역의 일반 주민들에게 미 
치는 영향이나 개인적 위험도(IR)는 낮음을 확인할 수 있었다. 하지만, BTX 물질은 사고 발생 우려가 높고, 사고가 발생하여 흡입할 경우 급성 중독을 일으키는 물질이며, CA결과 ERPG-2 농 도보다 높게 나오는 것 또한 무시할 수 없는 요소이다. BTX 물질 은 대기 중으로 배출 시 광화학반응(Photochemical reaction)에 의 하여 오존 등을 생성함에 따라 자체의 환경영향 및 2 차 반응에 의한 위험이 존재한다. 더불어 항만이라는 지역적인 특성을 고려 했을 때, 바다의 기상적인 상황이나 해상에서 발생할 수 있는 자 연재해에 의해 위험도가 급격히 증가할 가능성이 존재한다.

또한, $20 \mathrm{ft}(2.4 \times 2.4 \times 6(\mathrm{~m}))$ 와 더불어 많이 사용 되는 $40 \mathrm{ft}(2.4 \times 2.4 \times$ $12(\mathrm{~m})$ )의 컨테이너의 경우를 보았을 때의 IR은 근처의 다른 부두 와 주민들이 사용하는 도로에도 영향을 미치며, 특히 컨테이너를 적재함에 있어 $40 \mathrm{ft}(2.4 \times 2.4 \times 12(\mathrm{~m}))$ 기준 $2-5$ 개 $(20 \mathrm{ft}(2.4 \times 2.4 \times 6(\mathrm{~m}))$ 기준 5-10개)의 컨테이너의 연쇄적인 누출이 일어날 경우에는 화 재 등이 발생할 수 있으며, 주거지역에도 영향을 미칠 수 있다. 따라서 본 연구 결과가 항만에서 사고 발생 시 비상대응계획을 수립하고, 작업자 및 주거지역의 개인의 위험도 산정을 통해 사 고 시 피해를 최소화할 수 있는 예방 방안으로 활용될 것을 기대 한다.

현재 네덜란드의 경우, 새로운 시설 설치 시 개인적 위험도 (IR)는 $10^{-6} /$ year, 기존 시설에는 $10^{-5} /$ year로 제한하는 등 주거지 역의 위험도를 낮추기 위한 법을 시행하고 있다. 하지만 우리나 라의 경우에는 네덜란드와 달리 개인적 위험도(IR)를 제한하는 기준이 없기 때문에 항만 및 사업장에서도 이러한 기준을 적용 하기 위한 연구가 진행되어야 할 것이다.

\section{후기}

이 논문은 2015년도 정부(미래창조과학부)의 재원으로 한국연 구재단의 지원을 받아 수행된 기초연구(NRF-2015R1C1A1A0203 7491)입니다.

\section{References}

American Industrial Hygiene Association(AIHA), 2016. Emergency Response Planning Guidelines.

International Maritime Organization(IMO), 2014. IMDG Code. Kang, M.J., 2014. Planned Check / High Potential Tank Container Market. Monthly Maritime Korea, 488.

Kang, S.J., Lee, I.M., Moon, J.Y., Chon, Y.W., 2017. Risk Analysis of Ammonia Leak in the Refrigeration Manufacturing Facilities. Journal of the Korean Institute of Gas, 21(1), 43-51.

Kim, K.S., Son, C.Y., Shin, H.I., Lee, M.S., 1998. Structural Design of Cargo Handling System for the Yellow Sea Area. Journal of Ocean Engineering and Technology, 13(2), 18-25.
Kim, S.S., 2015. Hazardous Chemical Accidents in Ports. Monthly Maritime Korea, 502.

Kim, W.S., Choi, N.Y.H., Kim, D.H., 2016. A Study on the Improvement of Safety Management System for Dangerous Goods in Korean Ports. Korea Maritime Institute(KMI), 2016-12.

Korea Occupational Safety \& Health Agency(KOSHA), 2017. Material Safety Data Sheet, Benzene, Toluene, Xylene.

Korean Statistical Information Service(KOSIS), 2017. Statistical System. [Online] Available at $<\mathrm{http}$ ://kosis.kr/index/index.jsp $>$ [Accessed Sep 20, 2017].

Lees, F.P., 1996. Loss Prevention in the Process Industries. 2nd Edition, Butterworths-Heinemann.

Martins, M.R., Pestana, M.A., Souza, G.F.M., Schleder, A.M., 2016. Quantitative Risk Analysis of Loading and Offloading Liquefied Natural Gas(LNG) on a Floating Storage and Regasification Unit(FSRU). Journal of Loss Prevention in the Process Industries, 43. 626-653.

Meteorological Administration, 2017. Statistical System. [Online] Available at $<$ https://data.kma.go.kr/cmmn/main.do $>$ [Accessed Sep 20, 2017].

Ministry of Environment, 2007. Final Report of the $3^{\text {rd }}$ Chemical Distribution Survey. 11-1480000-000909-01.

Ministry of Oceans and Fisheries, 2016. Loading and Unloading of Dangerous Goods Container in Port(Manual).

Ministry of Oceans and Fisheries, 2017. Statistical System. [Online] Available at $<$ https://www.mof.go.kr/statPortal $>$ [Accessed Sep 21, 2017].

National Fire Protection Association(NFPA), 2017. Standard System for the Identification of the Hazards of Materials for Emergency Response. NFPA 704.

National Institute of Chemical Safety(NICS), 2015. ALOHA Guidelines. 2015-2.

National Institute of Chemical Safety(NICS), 2016. Technical Guidelines for Selecting Accident Scenarios. 4.

Oak, J.M., Kawg, Y.M., Hong, M.S., Jung, S.H., 2017. A Study on Safety Distance of Toxic Gas Leak Accident Using Hazard Modeling Program. Korean Journal of Hazardous Materials, 5(1), 83-89.

Reference Manual Bevi Risk Assessments(RIVM), 2009. Module C Modeling the Specific Bevi Categories. 3.2.

Uijt de Haag, P.A.M., Ale, B.J.M., 2005. Guidelines for Quantitative Risk Assessment. CPR 18E, Purple Book, RVIM.

Woo, Y.J., Lee, C.J., 2016. A study of Emergency Response for the Leakage Accident of Hazardous and Noxious Substances in a Port. Journal of the Korean Society of Safety, 31(6), 32-38. 